\title{
Clinical management of hemochromatosis: current perspectives
}

This article was published in the following Dove Press journal:

International Journal of Clinical Transfusion Medicine

9 March 2017

Number of times this article has been viewed

\author{
Pierre Brissot ${ }^{1}$ \\ Thibault Cavey ${ }^{1,2}$ \\ Martine Ropert ${ }^{1,2}$ \\ Pascal Guggenbuhl'1,3 \\ Olivier Loréal' \\ 'Inserm UMR99I, 'Laboratory \\ of Biochemistry, ${ }^{3}$ Department of \\ Rheumatology, University Hospital, \\ Rennes, France
}

Correspondence: Pierre Brissot Department of Hepatology, Faculty of Medicine, University of Rennes I, 2, Avenue Professor Léon Bernard, 35000 Rennes, France

Tel +33223235469

Email pierre.brissot@univ-rennesI.fr

\begin{abstract}
Hemochromatosis (HC) corresponds to systemic iron overload of genetic origin. Its spectrum covers $H F E$-related $\mathrm{HC}$, a frequent disease exclusively present in Caucasians; however, several entities of non-HFE-related $\mathrm{HC}$, which correspond to very rare disorders, have been observed in both Caucasian and non-Caucasian populations. In most $\mathrm{HC}$ forms, iron overload is explained by hepcidin deficiency, which increases iron delivery into the plasma from both duodenal and splenic sources, with subsequent organ iron deposition. The diagnosis depends on a noninvasive approach combining clinical, biological, and imaging data. The treatment remains largely based on phlebotomy therapy, which is rarely replaced with erythrocytapheresis or chelation therapy. Hepcidin supplementation represents the logical therapeutics of the future for all $\mathrm{HC}$ forms related to hepcidin deficiency.

Keywords: iron overload, HFE, ferroportin, hemojuvelin, transferrin receptor 2, hepcidin, phlebotomy
\end{abstract}

\section{Nosological and pathophysiological background}

Before considering the clinical management of hemochromatosis $(\mathrm{HC})$, it is of interest to update the following aspects.

\section{Terminology}

HC refers to systemic iron overload of genetic origin. Therefore, the term should not be applied to nongenetic forms of chronic iron overload, which occur in hematological situations, especially congenital anemias, ${ }^{1,2}$ due to multiple transfusions (and dyserythropoiesis) or following excessive parenteral iron supplementation. ${ }^{3}$ These disorders correspond to acquired forms of iron overload. Similarly, the term "hemosiderosis" should no longer be used for any form of iron overload.

\section{HC spectrum}

Following the discovery of the $H F E$ gene in $1996,{ }^{4}$ the nosological frame of $\mathrm{HC}$ has changed dramatically in two main aspects. First and foremost, it appeared that most previously reported $\mathrm{HC}$ cases were related to homozygosity of the HFE mutation $C 282 Y$ (p.Cys282Tyr) defining type $1 \mathrm{HC}$, but it also rapidly turned out that rare $\mathrm{HC}$ cases were non- $H F E$ related, and today four main types of non- $H F E \mathrm{HC}$ can be individualized. ${ }^{5}$ Type $2 \mathrm{HC}$ relates to mutations of the hemojuvelin (HFE2 or $H J V$ ) gene (type $2 \mathrm{~A} \mathrm{HC}$ ) or of the hepcidin (Hamp) gene (type 2B HC). Type 
$3 \mathrm{HC}$ refers to mutations of the transferrin receptor 2 (TFR2) gene. Type $4 \mathrm{HC}$ (also called ferroportin disease) corresponds to mutations of the ferroportin gene (SLC40A1). Hereditary aceruloplasminemia (HA), due to mutations of the ceruloplasmin $(C P)$ gene, should, in our view, be added to the scope of $\mathrm{HC}$ entities. It should be stressed that types 1-3 HC are very rare compared to HFE HC. The predictive frequency of $H F E$ pathogenic genotypes has been estimated at $1 / 1,000$ vs $1 / 5,000,000$ for type $2 \mathrm{~A} \mathrm{HC}$, vs $1 / 6,000,000$ for type $3 \mathrm{HC}$, and vs $1 / 180,000,000$ for type $2 \mathrm{~B} \mathrm{HC}$. However, the frequency for type $4 \mathrm{HC}$ was close to that for type $1 \mathrm{HC}$ $(1 / 1,300)$, probably due to the dominant nature of the disease (whereas all other $\mathrm{HC}$ forms are recessive diseases). ${ }^{6}$

\section{Pathophysiology}

When considering the mechanism of iron overload, the different $\mathrm{HC}$ forms can be divided into the following two main opposing categories (Figure 1).

\section{Iron overload due to increased plasma iron}

This mechanism, whose common denominator is hepcidin deficiency, applies to types 1-3 HC. In these settings, the corresponding mutations either decrease the hepatic production of hepcidin by altering the molecular cascade involved in its synthesis (types 1, 2A, and $3 \mathrm{HC}$ ) or totally prevent hepcidin synthesis (type 2B HC). Hepcidin is a small peptide, essentially produced by the liver, ${ }^{7}$ that is considered as the "iron hormone" since it regulates systemic iron homeostasis. ${ }^{8,9}$ A decrease in plasma hepcidin concentration leads to an increased plasma iron concentration by a double mechanism, enhanced intestinal absorption of iron, and enhanced release by the spleen of the iron originating from the normal degradation of old red blood cells (erythrophagocytosis). This double source of increased iron delivery into the plasma is due to the "activation" (caused by hepcidin deficiency) of the cell iron exporter function of ferroportin (particularly present at the duodenal and spleen levels). When the transport capacity of the plasma iron carrier transferrin (corresponding to the notion of transferrin saturation [TfSat]) is exceeded by the large amount of iron reaching the plasma, new forms of circulating iron appear. Plasma non-transferrin bound iron (NTBI) has the kinetic property to be very avidly uptaken by various organs (liver, pancreas, and heart), in contrast with transferrin-bound iron whose target is essentially the bone marrow (in order to produce new erythrocytes). ${ }^{10}$ NTBI is therefore likely to be responsible for the type of iron overload distribution occurring in hepcidin deficiency-related HC. Labile plasma iron (LPI) is an NTBI form defined by

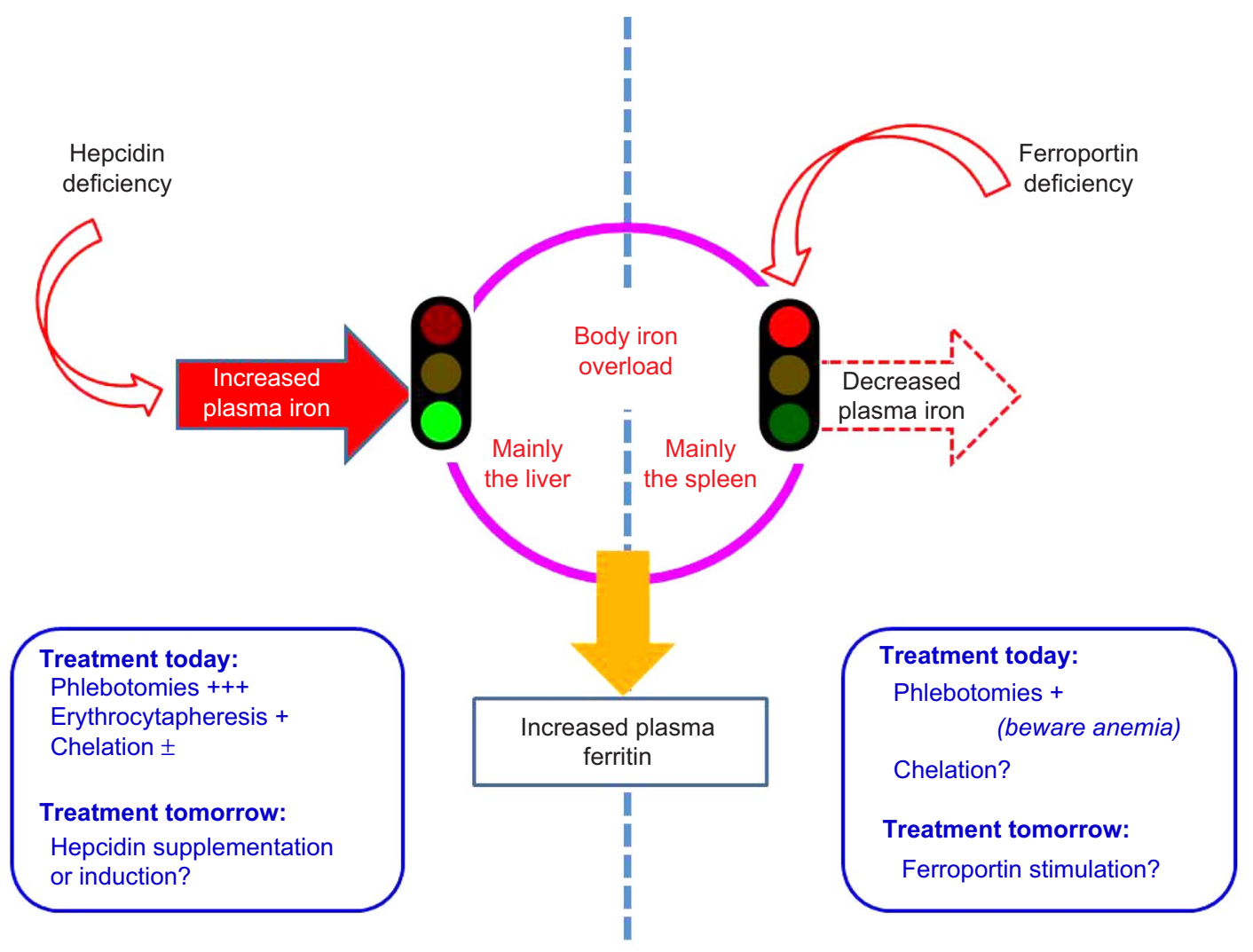

Figure I Pathophysiological and therapeutic aspects for the two most common forms of hemochromatosis. 
its potential cellular toxicity through its high propensity to generate reactive oxygen species ${ }^{11}$ and might be involved in $\mathrm{HC}$ tissue toxicity. ${ }^{12} \mathrm{~A}$ peculiar situation is hepcidin cell deprivation that is caused by mutations of the ferroportin gene affecting its other function, similar to that of hepcidin receptor, and not by decreased plasma hepcidin concentration. Then, a hepcidin resistance state develops ${ }^{13}$ whose consequences are similar to those following true plasma hepcidin deficiency (type 4B HC).

\section{Iron overload due to decreased plasma iron}

The typical situation is type $4 \mathrm{~A} \mathrm{HC}$, which is the most frequent form of ferroportin disease. ${ }^{14,15}$ The involved mutations affect the cell iron export function of ferroportin. Therefore, there is decreased cell iron delivery into the plasma causing iron overload by intracellular iron retention. Since ferroportin activity is especially pronounced in macrophages, iron overload will be mainly located in the spleen and within hepatic macrophages (Kupffer cells). This location (considered as less toxic than parenchymal iron overload), combined with the fact that neither NTBI nor LPI are expected to appear in the plasma (since TfSat is not increased and is in fact often decreased), accounts for the low damaging effects of this type of iron overload. ${ }^{16}$

\section{The case of HA}

It has been proposed that iron overload is due to cellular iron retention related to a decreased ferroxidase activity of $\mathrm{CP}$, which, in turn, would alter the cell export function of ferroportin, according to a mechanism similar to that involved in type 4A HC. ${ }^{17}$ This view fits with the decreased plasma iron levels with low transferrin saturation levels observed in this disease. However, it may not be the sole explanation when considering especially that, in HA, iron overload is mainly present in the liver and spares the spleen, an organ iron distribution that does not fit with the prevailing localization of ferroportin in the reticuloendothelial (macrophagic) system. Moreover, iron deposition occurs within the brain, in contrast with the other HC types. ${ }^{18}$

\section{Clinical management Diagnostic aspects} Clinical situations

Individuals of both sexes aged $>30$ years or younger (adolescents or adults $<30$ years) may be affected. The symptoms are as follows: chronic fatigue, impotence, arthropathies, osteoporosis, increased skin pigmentation, hepatic signs (hepatomegaly, mild cytolysis, sometimes cirrhosis, or hepatocellular carcinoma), diabetes, cardiac symptoms (rhythm disturbances and cardiac failure), rarely (limited to HA) anemia and neurological (extrapyramidal) symptoms.

\section{Hyperferritinemia}

Although low ferritin levels always rule out iron overload, hyperferritinemia is far from being synonymous of iron overload. It is therefore critical to exclude four main situations where hyperferritinemia is not (or only mildly) associated with iron overload. 1) Metabolic syndrome: ferritin levels can reach up to $1,000 \mu \mathrm{g} / \mathrm{L}$ (upper normal limits of the order of $300 \mu \mathrm{g} / \mathrm{L}$ in men and $200 \mu \mathrm{g} / \mathrm{L}$ in women). It can be recognized by the association of hyperferritinemia with one or more of the following dysmetabolic components: overweight, increased blood pressure, hyperlipidemia, diabetes, hyperuricemia (with sometimes gout), and hepatic symptoms related to steatosis (slight increase in plasma alanine amino transferase, aspartate amino transferase, and gammaglutamytranspeptidase [GGT] activities associated with liver hyperechogenicity at ultrasound examination). Plasma transferrin saturation is normal $(<45 \%)$. Hepatic iron overload is either absent or mild ${ }^{19}$ (contrasting with marked ferritin increase). 2) Chronic alcoholism: alcohol increases ferritin synthesis and should be especially evoked when ferritin levels show apparently spontaneous fluctuations, which are in fact explained by variations in the severity of alcohol consumption. It is therefore important to check biological signs of alcoholism such as increased GGT levels often associated with macrocytosis. 3) Inflammation: ferritin being an acute-phase reactant protein, it is good clinical practice to check CRP levels.

After exclusion of these confounding situations, hyperferritinemia can be considered as highly likely reflecting increased body iron stores.

\section{Magnetic resonance imaging}

Various techniques are available. Relaxometry approaches define indices called $\mathrm{T} 2 *$ and $\mathrm{R} 2 *{ }^{20,21}$ The simplest technique, in our practice, is based on the signal intensity ratio approach. ${ }^{22}$ It compares the magnetic resonance imaging (MRI) signal of the liver with that of the spinal muscles, which serve as the reference. This technique does not need any special MRI equipment, can refer to a diagnostic algorithm freely available on the web (http://www.radio.univrennes 1.fr/Sources/EN/HemoCalc15.html), and has shown its reliability; the decrease in T2 signal is inversely proportional to hepatic iron concentration. It can also evaluate, in the same way, spleen and pancreas iron load. 
MRI has largely replaced the liver biopsy, which is no more performed for the diagnosis of iron overload due to its invasiveness, except in case of MRI unavailability or contraindication or when liver biopsy could provide additional information, especially associated liver lesions or hepatic fibrosis (but even in the latter situation, biochemical tests of fibrosis ${ }^{23}$ combined with transient elastography ${ }^{24}$ are increasingly replacing histological determination).

\section{Determination of the genetic origin of iron overload}

Acquired iron overload should be excluded, which is usually easy by considering the following clinical background: chronic anemia necessitating numerous blood transfusions (mainly hemoglobinopathies such as thalassemia ${ }^{1}$ and sickle cell disease ${ }^{2}$ ) and excessive parenteral iron supplementation. ${ }^{3}$

Arguments favoring genetic origin should be collected. They may consist of suggestive family data and/or the young age at which iron overload has developed.

\section{Determination of the hemochromatosis type}

Types of hemochromatosis must finally be defined. Demographic background, plasma iron concentration, and MRI distribution of iron overload are the key orientating factors (Figure 1).

\section{Demographic background}

In a non-Caucasian individual, HFE (type 1) HC can be excluded. In contrast, non-HFE HC can occur in both Caucasian and non-Caucasian populations. ${ }^{6} \mathrm{~A}$ severe phenotype (massive iron overload, hypopituitarism, cardiomyopathy, and cirrhosis) in an adolescent or an adult younger than 30 years must suggest juvenile $\mathrm{HC}$ (essentially types $2 \mathrm{~A}$ and $2 \mathrm{~B} \mathrm{HC}$ but also possibly type $3 \mathrm{HC}$ ). In type $1 \mathrm{HC}$, severe clinical phenotype is usually expressed only after the age of 30 years.

\section{Plasma iron concentration (or transferrin saturation) levels}

High levels of plasma iron concentration are in favor of hepcidin-deficient (types 1-3) or hepcidin-resistant (type 4B) $\mathrm{HC}$, whereas low or normal levels suggest type $4 \mathrm{~A} \mathrm{HC}$ or HA.

\section{MRI distribution of iron overload}

A "black" (implying massively iron overloaded) liver with a white spleen (implying no iron overload) points to hepcidindeficient or -resistant HC. However, this imaging profile is also observed in HA. A black spleen and a "gray" (implying moderately iron overloaded) liver are in favor of ferroportin disease (type 4A).

\section{Guided genetic testing definitely identifies the $\mathrm{HC}$ type}

$C 282 Y$ homozygosity $(C 282 Y / C 282 Y)$ proves type $1 \mathrm{HC}$. It is no more recommended to search for the $H 63 D$ ( $p$.His63Asp) mutation. If nevertheless performed, $H 63 D$ heterozygosity must be considered as a simple polymorphism without pathological meaning. H63D homozygosity and compound heterozygosity $(C 282 Y / H 63 D)$ cannot lead to clinically significant iron overload (at most, they can be associated with an increase in transferrin saturation) but represent cofactors of hyperferritinemia and moderate hepatic iron overload in patients with alcoholism or metabolic syndrome. ${ }^{25}$ The search for non- $H F E$ mutations must be performed in highly specialized, accredited laboratories, following at best a prescription from a clinical reference center. ${ }^{25}$

\section{Therapeutic aspects}

The therapeutic management ${ }^{26}$ is focused, here, on the removal of iron overload (Figure 1).

\section{Type I HC}

\section{Phlebotomies}

Phlebotomies remain the mainstay of treatment and can be done in various settings (hospital, clinic, medical office, nurse office, and patient home ${ }^{27}$ ), their primary objective being to remove iron overload (implying induction phase). Performed on a weekly basis and withdrawing $\sim 7 \mathrm{~mL}$ of blood/kg body weight (upper limit $550 \mathrm{~mL}$ ) at each phlebotomy, ${ }^{28}$ their follow-up involves both tolerance (blood pressure and hemoglobin levels) and efficacy (clinical improvement and ferritin decrease). The objective is to reach plasma ferritin levels of $50 \mu \mathrm{g} / \mathrm{L}$ and, thereafter, start the maintenance phase that aims at preventing progressive reconstitution of iron overload and theoretically extends throughout the life. Phlebotomies are usually performed every $2-4$ months for maintaining ferritinemia $\sim 50 \mu \mathrm{g} / \mathrm{L}$. Regarding the purpose of checking plasma TfSat levels, the following view can be proposed: 1) during most of the induction phase, evaluating TfSat has no indication because it remains high as long as plasma ferritin has not yet reached the normal range; however, it becomes useful to ascertain correct "de-ironing" at the very end of this induction phase; 2) during maintenance therapy, considering that the "natural" propensity for increasing TfSat remains high in HC patients, it may be interesting to check this parameter, for instance twice a year, in order to detect persistent major elevation of TfSat ( $>75 \%)$ despite appropriate $(50 \mu \mathrm{g} / \mathrm{L})$ ferritin levels. Indeed, it has been shown that such high TfSat levels are 
often associated with the appearance of LPI, the potentially toxic form of plasma iron. Globally, phlebotomy therapy is well tolerated, although a large sample size study has shown that significant side effects can be observed, with some impact on the quality of life. ${ }^{29}$ In terms of efficacy, most syndromes are improved (general health, hyperpigmentation, and hepatic and cardiac symptoms), and a normal life expectancy can be restored. However, arthropathy is largely refractory to this treatment and can even worsen. ${ }^{30,31}$ In an increasing number of countries, the blood originating from $\mathrm{HC}$ patients is accepted for subsequent blood transfusions. ${ }^{32,33}$

\section{Erythrocytapheresis ${ }^{34-36}$}

Although more complex and expensive, erythrocytapheresis, which remains rarely applied in $\mathrm{HC}$, is more efficient than phlebotomies and is globally well accepted by the patients.

\section{Chelation therapy}

It can be proposed for the exceptional cases of contraindications to phlebotomies or of technical impossibility (poor venous status). Prolonged subcutaneous infusions of desferrioxamine can then be proposed, and, if poorly tolerated, an oral chelator (such as deferasirox ${ }^{37,38}$ ) remains an "off-label" possibility (under the responsibility of the medical prescriber and with written informed consent of the patient).

\section{Non-HFE HC}

\section{Types 2A and 2B HC}

Due to the severity of iron overload, phlebotomies can be used in combination with parenteral (desferrioxamine) or oral (deferasirox ${ }^{39}$ as an off-label drug) chelation.

\section{Type $3 \mathrm{HC}$}

The phlebotomy schedule for type $3 \mathrm{HC}$ is similar to that for type $1 \mathrm{HC}$.

\section{Type $4 \mathrm{HC}$}

The phlebotomies for type $4 \mathrm{HC}$ are as follows. 1) Type 4A HC: the impaired capacity for cellular iron export accounts for diminished efficacy and tolerance (risk of anemia) of phlebotomies; therefore, a softer subtraction schedule is advised (usually one phlebotomy every 2 weeks) with careful follow-up of hemoglobin levels. ${ }^{16}$ Whether oral chelation could be beneficial requires further studies. ${ }^{40}$ 2) Type 4B HC: the phlebotomy schedule for this type $4 \mathrm{~B} \mathrm{HC}$ is similar to that for type $1 \mathrm{HC}$.

\section{HA}

Phlebotomies are contraindicated due to anemia. Parenteral or oral chelation gives partial results. ${ }^{41-44}$

\section{The therapeutic future for counteracting iron overload}

Withdrawing iron by phlebotomies (and/or chelation) is only a symptomatic approach; therefore, hepcidin supplementation (or induction) in all forms of hepcidin deficiency-related $\mathrm{HC}^{45,46}$ is an attractive option. It could be used as an adjunct to phlebotomy therapy during the induction phase and as a possible substitute to phlebotomies during the maintenance period, provided a well-tolerated, oral, and affordable compound can be designed.

Therapeutic management of HC must, of course, involve a preventive dimension. As soon as one case of $\mathrm{HC}$ has been diagnosed, the proband's family should benefit from HC screening, especially based on appropriate genetic testing and control of plasma iron parameters (ferritin and TfSat).

\section{Conclusion}

$\mathrm{HC}$ encompasses a variety of genetic iron overload disorders, $H F E$-related $\mathrm{HC}$ being by far the most frequent entity. The diagnosis is based on a rigorous noninvasive strategy combining clinical data, plasma ferritin and transferrin saturation determinations, liver (and spleen) iron-MRI profile, and appropriate genetic testing. For most of the $\mathrm{HC}$ forms related to hepcidin deficiency, phlebotomies offer a simple and globally well-tolerated method to remove iron overload and improve significantly the quality of life and life expectancy. However, the future therapeutic approach, based on the molecular understanding of these diseases, should consist of hepcidin supplementation (or induction) calibrated so as to restore normal iron homeostasis.

\section{Acknowledgment}

The authors wish to thank the financial support from EuroIron1 (European Community Grant), IronReg (French National Research Agency), Novartis, AHO (Association Hémochromatose Ouest), and Afemers (Association Fer-Métaux essentiels-Recherche-Santé).

\section{Disclosure}

The authors report no conflicts of interest in this work.

\section{References}

1. Coates TD, Carson S, Wood JC, Berdoukas V. Management of iron overload in hemoglobinopathies: what is the appropriate target iron level? Ann N Y Acad Sci. 2016;1368(1):95-106. 
2. Wood JC, Cohen AR, Pressel SL, et al. Organ iron accumulation in chronically transfused children with sickle cell anaemia: baseline results from the TWiTCH trial. Br J Haematol. 2016;172(1):122-130.

3. Macdougall IC, Bircher AJ, Eckardt KU, et al. Iron management in chronic kidney disease: conclusions from a "kidney disease: improving global outcomes" (KDIGO) controversies conference. Kidney Int. 2016;89(1):28-39.

4. Feder JN, Gnirke A, Thomas W, et al. A novel MHC class I-like gene is mutated in patients with hereditary haemochromatosis. Nat Genet. 1996;13(4):399-408.

5. Brissot $\mathrm{P}$, Bardou-Jacquet $\mathrm{E}$, Jouanolle AM, Loreal O. Iron disorders of genetic origin: a changing world. Trends Mol Med. 2011;17(12): $707-713$.

6. Wallace DF, Subramaniam N. The global prevalence of HFE and nonHFE hemochromatosis estimated from analysis of next-generation sequencing data. Genet Med. 2016;18(6):618-626.

7. Pigeon C, Ilyin G, Courselaud B, et al. A new mouse liver-specific gene, encoding a protein homologous to human antimicrobial peptide hepcidin, is overexpressed during iron overload. $J$ Biol Chem. 2001;276(11):7811-7819.

8. Nicolas G, Bennoun M, Devaux I, et al. Lack of hepcidin gene expression and severe tissue iron overload in upstream stimulatory factor 2 (USF2) knockout mice. Proc Natl Acad Sci U S A. 2001;98(15):8780-8785.

9. Ganz T. Systemic iron homeostasis. Physiol Rev. 2013;93(4):1721-1741.

10. Brissot P, Ropert M, Le Lan C, Loreal O. Non-transferrin bound iron: a key role in iron overload and iron toxicity. Biochim Biophys Acta. 2012;1820(3):403-410.

11. Cabantchik ZI. Labile iron in cells and body fluids: physiology, pathology, and pharmacology. Front Pharmacol. 2014;5:45.

12. Le Lan C, Loreal O, Cohen T, et al. Redox active plasma iron in $\mathrm{C} 282 \mathrm{Y} /$ C282Y hemochromatosis. Blood. 2005;105(11):4527-4531.

13. Drakesmith H, Schimanski LM, Ormerod E, et al. Resistance to hepcidin is conferred by hemochromatosis-associated mutations of ferroportin. Blood. 2005;106(3):1092-1097.

14. Montosi G, Donovan A, Totaro A, et al. Autosomal-dominant hemochromatosis is associated with a mutation in the ferroportin (SLC11A3) gene. J Clin Invest. 2001;108(4):619-623.

15. Njajou OT, Vaessen N, Joosse M, et al. A mutation in SLC11A3 is associated with autosomal dominant hemochromatosis. Nat Genet. 2001;28(3):213-214.

16. Le Lan C, Mosser A, Ropert M, et al. Sex and acquired cofactors determine phenotypes of ferroportin disease. Gastroenterology. 2011;140(4): e1-e2.

17. De Domenico I, Ward DM, di Patti MC, et al. Ferroxidase activity is required for the stability of cell surface ferroportin in cells expressing GPI-ceruloplasmin. EMBO J. 2007;26(12):2823-2831.

18. Brissot P, Loreal O. Iron metabolism and related genetic diseases: a cleared land, keeping mysteries. J Hepatol. 2016;64(2):505-515.

19. Jézéquel C, Lainé F, Laviolle B, Kiani A, Bardou-Jacquet E, Deugnier Y. Both hepatic and body iron stores are increased in dysmetabolic iron overload syndrome. A case-control study. PLoS One. 2015;10(6): $\mathrm{e} 0128530$.

20. Wood JC. Estimating tissue iron burden: current status and future prospects. Br J Haematol. 2015;170(1):15-28.

21. St Pierre TG, Clark PR, Chua-anusorn W, et al. Noninvasive measurement and imaging of liver iron concentrations using proton magnetic resonance. Blood. 2005;105(2):855-861.

22. Gandon Y, Olivie D, Guyader D, et al. Non-invasive assessment of hepatic iron stores by MRI. Lancet. 2004;363(9406):357-362.

23. Chin JL, Pavlides M, Moolla A, Ryan JD. Non-invasive markers of liver fibrosis: adjuncts or alternatives to liver biopsy? Front Pharmacol. 2016;7:159.

24. Legros L, Bardou-Jacquet E, Latournerie M, et al. Non-invasive assessment of liver fibrosis in $\mathrm{C} 282 \mathrm{Y}$ homozygous HFE hemochromatosis. Liver Int. 2015;35(6):1731-1738.
25. Porto G, Brissot P, Swinkels DW, et al. EMQN best practice guidelines for the molecular genetic diagnosis of hereditary hemochromatosis (HH). Eur J Hum Genet. 2016;24(4):479-495.

26. Brissot P. Optimizing the diagnosis and the treatment of iron overload diseases. Expert Rev Gastroenterol Hepatol. 2016;10(3):359-370.

27. Manea P, Loustaud-Ratti V, Mondary D, et al. Evaluation of at-home phlebotomy for iron overload: feasibility and satisfaction of patients and healthcare workers. Gastroenterol Clin Biol. 2008;32(2):172-179.

28. HAS [homepage on the Internet]. French Recommendations for Management of HFE Hemochromatosis. Haute Autorité de Santé; 2005. www. has-sante.fr. Accessed September 1, 2016.

29. Brissot P, Ball S, Rofail D, Cannon H, Jin VW. Hereditary hemochromatosis: patient experiences of the disease and phlebotomy treatment. Transfusion. 2011;51(6):1331-1338.

30. Guggenbuhl P. Atteintes articulaires de l'hémochromatose [Joint involvement in hemochromatosis]. Rev Prat. 2015;65(5):678-679. French.

31. Pascart T, Richette P, Flipo RM. Treatment of nongout joint deposition diseases: an update. Arthritis. 2014;2014:375202.

32. Marrow B, Clarkson J, Chapman CE, Masson S. Facilitation of blood donation amongst haemochromatosis patients. Transfus Med. 2015;25(4):239-242.

33. Pauwels NS, De Buck E, Compernolle V, Vandekerckhove P. Worldwide policies on haemochromatosis and blood donation: a survey among blood services. Vox Sang. 2013;105(2):121-128.

34. Rombout-Sestrienkova E, Koek GH, Neslo R, et al. Course of iron parameters in HFE-hemochromatosis patients during initial treatment with erythrocytapheresis compared to phlebotomy. J Clin Apher. Epub 2016 Feb 16.

35. Rombout-Sestrienkova E, Winkens B, Essers BA, et al. Erythrocytapheresis versus phlebotomy in the maintenance treatment of HFE hemochromatosis patients: results from a randomized crossover trial. Transfusion. 2016;56(1):261-270.

36. Sundic T, Hervig T, Hannisdal S, et al. Erythrocytapheresis compared with whole blood phlebotomy for the treatment of hereditary haemochromatosis. Blood Transfus. 2014;12(suppl 1):s84-s89.

37. Phatak $P$, Brissot $P$, Wurster $M$, et al. A phase $1 / 2$, dose-escalation trial of deferasirox for the treatment of iron overload in HFE-related hereditary hemochromatosis. Hepatology. 2010;52(5):1671-1779.

38. Cancado R, Melo MR, de Moraes Bastos R, et al. Deferasirox in patients with iron overload secondary to hereditary hemochromatosis: results of a 1-yr Phase 2 study. Eur J Haematol. 2015;95(6):545-550.

39. Santos PC, Cancado RD, Pereira AC, et al. HJV hemochromatosis, iron overload, and hypogonadism in a Brazilian man: treatment with phlebotomy and deferasirox. Acta Haematol. 2010;124(4):204-205.

40. Unal S, Piperno A, Gumruk F. Iron chelation with deferasirox in a patient with de-novo ferroportin mutation. J Trace Elem Med Biol. 2015;30:1-3.

41. Loreal O, Turlin B, Pigeon C, et al. Aceruloplasminemia: new clinical, pathophysiological and therapeutic insights. $J$ Hepatol. 2002;36(6):851-856.

42. Finkenstedt A, Wolf E, Hofner E, et al. Hepatic but not brain iron is rapidly chelated by deferasirox in aceruloplasminemia due to a novel gene mutation. J Hepatol. 2010;53(6):1101-1107.

43. Skidmore FM, Drago V, Foster P, Schmalfuss IM, Heilman KM, Streiff RR. Aceruloplasminaemia with progressive atrophy without brain iron overload: treatment with oral chelation. J Neurol Neurosurg Psychiatry. 2008;79(4):467-470.

44. SuzukiY,Yoshida K, Aburakawa Y, et al. Effectiveness of oral iron chelator treatment with deferasirox in an aceruloplasminemia patient with a novel ceruloplasmin gene mutation. Intern Med. 2013;52(13):1527-1530.

45. Ramos E, Ruchala P, Goodnough JB, et al. Minihepcidins prevent iron overload in a hepcidin-deficient mouse model of severe hemochromatosis. Blood. 2012;120(18):3829-3836.

46. Fung E, Nemeth E. Manipulation of the hepcidin pathway for therapeutic purposes. Haematologica. 2013;98(11):1667-1676. 
International Journal of Clinical Transfusion Medicine is an international, peer-reviewed, open access, online journal publishing clinicalexperimental, policy-making and evidence-based practices of all topics pertaining to clinical transfusion medicine. Original research, short reports, reviews, case reports and commentaries are invited.
The manuscript management system is completely online and includes a very quick and fair peer-review system, which is all easy to use. Visit http://www.dovepress.com/testimonials.php to read real quotes from published authors.

Submit your manuscript here: https://www.dovepress.com/international-journal-of-clinical-transfusion-medicine-journal 